\title{
Alimentação Saudável: \\ Contribuições de uma Sequência Didática Interativa Para o Ensino de Ciências nos Anos Iniciais
}

\author{
Rosemar de Fátima Vestena ${ }^{1}$ \\ Greice Scremin ${ }^{2}$ \\ Giséli Duarte Bastos ${ }^{3}$
}

\begin{abstract}
$\underline{\text { Resumo }}$
0 trabalho analisou a adequação de uma Sequência Didática Interativa (SDI), que explorou a temática da alimentação saudável, as competências específicas para as Ciências da Natureza (CNs) propostas pela Base Nacional Comum Curricular (BNCC) e os Conteúdos Conceituais, Procedimentais e Atitudinais (ZABALA, 1998) adaptados às particularidades das CNs. A SDI foi desenvolvida em uma turma de 5o ano dos anos iniciais do Ensino Fundamental de uma escola pública do município de Santa Maria-RS, localizada em região periférica da cidade. A sequência envolveu uma diversidade metodológica, como: leituras, pesquisas, discussões em grupo, produção de textos, gráficos e desenhos. Na pesquisa, de abordagem qualitativa, bibliográfica e documental, foram analisados os planos de trabalho de uma professora ao desenvolver a SDI e os registros dos estudantes ao participarem. Como resultado, percebeu-se a adequação das etapas da SDI às competências das CNs estabelecidas pela BNCC, bem como algumas evidências do desenvolvimento dessas nos estudantes participantes. Além disso, os três conteúdos foram contemplados em diversos momentos da sequência. Dessa forma, a SDI trabalhada auxiliou na formação das crianças ao possibilitar o conhecimento sobre alimentação saudável e ao instrumentalizar as tomadas de decisão quanto aos hábitos alimentares que irão adotar a partir de então.
\end{abstract}

Palavras-chave: Educação científica. Educação alimentar. Ensino Fundamental. Metodologia de ensino.

1 Professora no Centro Universitário Franciscano (Unifra), doutora em Educação em Ciências (UFSM). rosemarvestena@gmail.com

2 Professora no Centro Universitário Franciscano (Unifra), doutora em Educação (UFSM). greicescremin@gmail.com

${ }^{3}$ Doutoranda em Educação em Ciências (UFSM). giselibastos@gmail.com 


\title{
HEALTHY EATING: CONTRIBUTIONS OF AN INTERACTIVE DIDACTIC SEQUENCE FOR THE TEACHING OF SCIENCES IN THE INITIAL YEARS OF ELEMENTARY EDUCATION
}

\begin{abstract}
The study analyzed the adequacy of an Interactive Didactic Sequence (SDI), which explored the theme of healthy eating, the competences proposed by the National Curricular Joint Base (BNCC) and the Conceptual, Procedural and Attitudinal Contents (ZABALA, 1998) adapted to the needs of Science of Nature. The SDI was developed in a fifth year class of the initial years of elementary education, from a public school in the municipality of Santa Maria-RS, located in the peripheral region of the city. The sequence involved a methodological diversity, such as: reading, research, group discussions, text production, graphics and drawings. In the qualitative, bibliographical and documentary research, the work plans of a teacher were analyzed when developing the SDI and the students' records when participating. As a result, the appropriateness of the SDI stages to the competences established by the BNCC was verified, as well as some evidence of the development of the three contents in the participating students. In this way, the SDI worked helped in the training of children by making possible the knowledge about healthy eating and instrumentalizing the decision making regarding the eating habits that they will adopt from then on.
\end{abstract}

Keywords: Scientific education. Nutrition education. Elementary School. Teaching Methodology.

Recebido em: 10/7/2017

Aceito em: 3/12/2017 
Tendo em vista as constantes transformações científicas e tecnológicas da sociedade contemporânea, torna-se relevante considerar a formação científica dos cidadãos para compreenderem os fenômenos da natureza e, principalmente, para atuarem no mundo com maior autonomia e responsabilidade social.

Nesse contexto, faz-se necessário repensar hábitos alimentares e a relação que os diferentes sujeitos constroem com a alimentação. De acordo com Accioly (2009), os hábitos alimentares, comumente, são estabelecidos durante os primeiros anos de vida e fazem parte da cultura e da identidade dos povos e nações, sendo modificáveis por pressões econômicas, sociais e culturais. Assim sendo, mesmo antes de iniciarem a vida escolar, as crianças já trazem consigo uma cultura alimentar influenciada pela família, pela sociedade e pela mídia. A alimentação infantil sofre forte influência do padrão familiar, considerada a família como o primeiro núcleo de integração social do ser humano (ACCIOLY, 2009).

Nos últimos anos as dietas, as atitudes e os hábitos alimentares vêm se alterando. O Brasil, a exemplo de outros países em desenvolvimento, experimenta a chamada transição nutricional, caracterizada pela concomitância de situações de má nutrição resultantes de deficiências nutricionais e as decorrentes de excessos alimentares (PATARRA, 2006). Os alimentos, cada vez mais, apresentam excesso de gorduras, sal, açúcares, amido, corantes, aditivos químicos, etc. Além disso, o hábito de preparar a própria comida vem sendo abandonado pelas famílias devido à grande disponibilidade de alimentos industrializados, aliada à falta de tempo característica da sociedade contemporânea.

Constata-se, ainda, uma significativa diminuição dos gastos calóricos diários ao se minimizar esforços físicos para se deslocar ao trabalho, à escola, para brincar, para ligar/desligar aparelhos, subir escadas, etc. Esse comportamento, aliado à dieta empobrecida de nutrientes e com elevado teor calórico, tem ocasionado uma série de distúrbios de alto impacto epidemiológico, destacando-se as doenças cardiovasculares, a diabete, a hipertensão arterial, câncer, obesidade e dislipidemias (alterações nas frações de gorduras no sangue) (GONÇALVES et al., 2008). No Brasil, segundo dados do IBGE, 36,6\% das crianças encontram-se obesas ou com sobrepeso (INSTITUTO..., 2003). 
Entende-se que a alimentação é um ato não apenas fisiológico, mas também de integração social e, portanto, fortemente influenciada pelas experiências a que são submetidas as crianças em seus círculos de convivência (ACCIOLY, 2009). A escola, como espaço de convivência e de troca de vivências, desempenha um papel-chave de aprendizagem e mudança de comportamento quanto à alimentação, seja por meio da merenda escolar, seja pelas práticas pedagógicas desenvolvidas com os alunos que tenham relação com a temática.

Conforme definido na Lei de Diretrizes e Bases para a Educação Nacional (LDB, Lei no 9.394/1996) (BRASIL, 1996), a Base Nacional Comum Curricular - BNCC (BRASIL, 2017), documento de caráter normativo, deve nortear os currículos dos sistemas e redes de ensino e as propostas pedagógicas de todas as escolas brasileiras. A BNCC passa a definir o conjunto orgânico e progressivo de aprendizagens essenciais que todos os alunos devem desenvolver ao longo das etapas e modalidades da Educação Básica e está organizada em termos de competências. No âmbito da BNCC, a noção de competência é utilizada no sentido da mobilização e aplicação dos conhecimentos escolares, entendidos de forma ampla (conceitos, procedimentos, valores e atitudes). Assim, ser competente significa ser capaz de, ao se defrontar com um problema, ativar e utilizar o conhecimento construído (BRASIL, 2017).

No que respeita às Ciências da Natureza (CNs), dotar os estudantes de conhecimentos acerca dos conceitos e procedimentos, visando a atitudes científicas e críticas, é um dos grandes desafios na atualidade (ZABALA, 2007). Parte-se do princípio de que o aluno, ao compreender as ciências, correlacione-as ao seu cotidiano e saiba utilizá-las de forma consciente, como no caso de uma alimentação mais saudável. Diante dessas demandas, emerge a necessidade de alfabetizar cientificamente os cidadãos, isto é, dar-lhes um conjunto de conhecimentos capaz de facilitar a realização de uma leitura do mundo em que vivem (CHASSOT, 2006).

Isso posto, o presente trabalho teve como objetivo analisar a adequação de uma Sequência Didática Interativa (SDI) sobre alimentação saudável às competências específicas para as Ciências da Natureza (CNs) descritas na BNCC e aos Conteúdos Conceituais, Procedimentais e Atitudinais (ZABALA, 1998) 
adaptados às demandas das CNs. A atividade foi desenvolvida com alunos do $5^{\circ}$ ano do Ensino Fundamental de uma escola pública do município de Santa Maria, Rio Grande do Sul, Brasil. A partir da pesquisa, buscou-se revelar possíveis competências e conteúdos trabalhados na SDI que auxiliem na formação das crianças e possibilitem a tomada de consciência de seus hábitos alimentares, com potencialidades de interferir na melhoria da qualidade de sua vida e das pessoas com quem convivem.

\section{Referencial Teórico}

Comer, para a espécie humana, não é apenas uma necessidade de sobrevivência ou resposta a um estímulo, pois, além de garantir a energia necessária para as atividades metabólicas necessárias ao desenvolvimento, ao crescimento e à realização de atividades do corpo biológico, o ato de se alimentar, segundo Valadão (2003), também está associado ao prazer, ao lazer, às comemorações, à ansiedade, etc. Os hábitos e rituais culinários das diferentes culturas e de ambientes da Terra revelam muito da identidade e da história de vida de um povo. Ainda segundo a autora, o conjunto de alimentos que se ingere diariamente constitui a dieta alimentar de um indivíduo. "Em todas elas, é importante considerar a qualidade e a quantidade dos alimentos, a sua combinação e a higiene na sua preparação" (VALADÃO, 2003, p. 36).

Considerando a população brasileira e, em especial os jovens e crianças que frequentam a escola, o Conselho Nacional de Saúde tomou providências legais emitindo em 2008 a Resolução no 408/08 visando à promoção da alimentação saudável e reversão da epidemia de obesidade no país, bem como a prevenção de doenças crônicas não transmissíveis. Sendo assim, determina:

[...] oferta contínua de programas estatais de segurança alimentar e nutricional, voltados à alimentação saudável, com alimentos produzidos preferencialmente pela agricultura familiar, que incluam a oferta a preços acessíveis de frutas, legumes e verduras, cereais e grãos integrais, a educação alimentar e nutricional e o monitoramento nutricional em todos os ciclos de vida, garantidos por meio da Estratégia de Saúde da Família entre outras e consoantes 
com os princípios do desenvolvimento sustentável; promoção de alimentação saudável durante o ciclo escolar, adequada às necessidades das faixas etárias e grupos com necessidades especiais, e incentivo à atividade física, com ênfase na formação de hábitos saudáveis, através de ações articuladas da Estratégia Saúde da Família e do Programa Saúde na Escola, devendo, ainda, ser proibida a utilização de alimentos que contenham quantidades elevadas de açúcar, gorduras saturadas, gorduras trans, sódio e bebidas com baixo teor nutricional (BRASIL, 2008, p. 1).

Também como uma forma de regulamentar a alimentação escolar que geralmente é adquirida pelos gestores das escolas e ofertada gratuitamente aos estudantes na forma de merenda escolar, a lei 11.947/2009 determina no seu artigo $2^{\circ}$ as diretrizes da alimentação escolar visando:

O emprego da alimentação saudável e adequada, compreendendo o uso de alimentos variados, seguros, que respeitem a cultura, as tradições e os hábitos alimentares saudáveis, contribuindo para o crescimento e o desenvolvimento dos alunos e para a melhoria do rendimento escolar, em conformidade com a sua faixa etária e seu estado de saúde, inclusive dos que necessitam de atenção específica (BRASIL, 2009).

Desse modo a escola, por meio do currículo, necessita incluir temáticas e atividades que visem à conscientização de práticas alimentares saudáveis. Já que no artigo $2^{\circ}$ das diretrizes da alimentação escolar constam

a inclusão da educação alimentar e nutricional no processo de ensino e aprendizagem, que perpassa pelo currículo escolar, abordando o tema alimentação e nutrição e o desenvolvimento de práticas saudáveis de vida, na perspectiva da segurança alimentar e nutricional (BRASIL, 2009).

Destaca-se, nesse sentido, o papel da escola como principal instituição formal para atender à formação das crianças no que diz respeito aos conteúdos das áreas de conhecimento. O ponto de partida para novos conhecimentos, portanto, deve considerar a percepção prévia dos estudantes sobre o mundo natural e social em que estão imersos e isso inclui os hábitos para uma alimentação saudável. 
Sobre esse aspecto faz-se necessário que o Ensino Fundamental, especialmente os anos iniciais, tenham um compromisso com o desenvolvimento da alfabetização científica, que envolve a "capacidade de compreender e interpretar o mundo (natural, social e tecnológico), mas também de transformá-lo com base nos aportes teóricos e processuais da ciência" (BRASIL, 2017, p. 273). É nesse sentido que a escola precisa agir para o desenvolvimento da capacidade de atuação sobre o contexto, atitude importante para o exercício pleno da cidadania.

Assim, presume-se que, mediados pelos conhecimentos científicos, os estudantes possam desenvolver o senso crítico e se envolver, de fato, em processos de aprendizagem nos quais formulem e verifiquem hipóteses presentes em seu ambiente, em seus hábitos e atitudes, incluindo as suas experiências alimentares. Segundo Morais e Andrade (2009),

com relação aos alunos, a ciência está presente em seu cotidiano em vários contextos que independem do estudo de Ciências na escola: em desenhos animados, na Internet, em filmes, na literatura e, especialmente, no uso que eles fazem de produtos tecnológicos (alimentos, roupas, vacinas, tratamentos médicos e odontológicos, meios de transporte, brinquedos, equipamentos eletrônicos e outros) (p. 9).

Dessa forma, o papel da escola na educação científica está em mediar junto aos estudantes o domínio de vocabulário, simbolismos, fatos, conceitos, princípios e procedimentos da ciência; as características do "fazer ciência"; as relações entre ciência, tecnologia, sociedade e ambiente para entender o mundo atuando, avaliando e transformando a realidade (BRASIL, 2015).

Zabala (1998) aborda que, numa proposta curricular, os conteúdos podem ser trabalhados em uma perspectiva de totalidade dos saberes. Segundo o autor, esses foram categorizados em Conteúdos Conceituais (CCs) que remetem ao que o aluno "deve saber", englobando os conhecimentos construídos pela humanidade ao longo da História, referindo-se aos fatos princípios e conceitos. Destaca a necessidade de se trabalhar os Conteúdos Procedimentais (CPs), "saber fazer”, que possibilitam formular perguntas e suposições, organizar e registrar informações, envolvendo tomadas de decisão e reflexões de maneira ordenada para atingir os objetivos. Tais conteúdos viabilizam que o aluno olhe o mundo e 
seu contexto com maior autonomia, responsabilidade, postura crítica e reflexiva referente aos diferentes assuntos estudados. E, Conteúdos Atitudinais (CAs), em que os estudantes "devem ser", os quais supõem reflexão sobre valores, atitudes e condutas. Esse grupo de conteúdos é o que mais intensamente permite a inserção do indivíduo na comunidade e que melhor representa o ensino para a cidadania.

Assim, os conteúdos destacados por Zabala $(1998 ; 2007)$ estão diretamente relacionados ao ensino de Ciências nos anos iniciais do Ensino Fundamental, em conformidade com a terceira versão da BNCC (BRASIL, 2017). Nesse sentido, a área de Ciências da Natureza é o mote deste trabalho a partir do desenvolvimento de uma sequência didática interativa (SDI), tendo em vista que essa última trata de uma abordagem metodológica também alinhada com os objetivos para o ensino de Ciências da BNCC.

A BNCC, fruto de um amplo processo de debate com diferentes atores do campo educacional e com a sociedade brasileira em geral, é um documento que apresenta os Direitos e Objetivos de Aprendizagem e Desenvolvimento que devem orientar a elaboração de currículos para as diferentes etapas de escolarização.

Nesse sentido, BNCC é uma exigência colocada para o sistema educacional brasileiro pela Lei de Diretrizes e Bases para a Educação Nacional (BRASIL, 1996), pelas Diretrizes Curriculares Nacionais Gerais da Educação Básica (BRASIL, 2010) e pelo Plano Nacional de Educação (BRASIL, 2014a) e deve ser entendida como um avanço na construção da qualidade da educação. Dessa forma, a principal finalidade da BNCC é orientar os sistemas na elaboração de suas propostas curriculares.

A BNCC (2017), então, destaca sobre o ensino de Ciências da Natureza que

[...] o ensino de Ciências, como parte de um processo contínuo de contextualização histórica, social e cultural, dá sentido aos conhecimentos para que os/as estudantes compreendam, expliquem e intervenham no mundo em que vivem, estabelecendo relações entre os conhecimentos científicos e a sociedade, reconhecendo fatores que podem influenciar as transformações de uma dada realidade (p. 136). 
Para o Ensino Fundamental, a BNCC compromete-se com o desenvolvimento da alfabetização científica "que envolve a capacidade de compreender e interpretar o mundo (natural, social e tecnológico), mas também de transformá-lo com base nos aportes teóricos e processuais da ciência" (BRASIL, 2017, p. 273). Dessa forma, esse documento considera fundamental a compreensão da articulação entre os distintos campos do saber, bem como o desenvolvimento da familiaridade com processos, práticas e procedimentos de investigação científica para a apropriação dos conhecimentos da área de Ciências da Natureza.

Para tanto, a BNCC

[...] pressupõe organizar as situações de aprendizagem partindo de questões que sejam desafiadoras, estimulem o interesse e a curiosidade científica dos alunos e possibilitem definir problemas, levantar, analisar e representar resultados; comunicar conclusões e propor intervenções (BRASIL, 2017, p. 274).

Foi nesse sentido que a SDI foi planejada e proposta, a fim de que os estudantes vivenciassem distintas formas de analisar e representar resultados inerentes aos conteúdos presentes na temática da alimentação saudável.

A título de organização de conteúdos para anos iniciais, a BNCC (BRASIL, 2017) prevê três unidades temáticas para a área de Ciências da Natureza que se repetem ao longo do Ensino Fundamental:

- Unidade temática Matéria e Energia - contempla o estudo de materiais e suas transformações, fontes e tipos de energia utilizados na vida em geral, na perspectiva de construir conhecimento sobre a natureza da matéria e dos diferentes usos da energia [...] (BRASIL, 2017, p. 277).

- Unidade temática Terra e Universo - busca-se a compreensão de características da Terra, do Sol, da Lua e de outros corpos celestes, suas dimensões, composição, localizações, movimentos e forças que atuam entre eles [...] (BRASIL, 2017, p. 280).

Este trabalho voltou-se objetivamente para a terceira unidade temática: Vida e Evolução, a qual "propõe o estudo de questões relacionadas aos seres vivos (incluindo os seres humanos), suas características e necessidades" (BRASIL, 2017, p. 278). De acordo com o documento, as características dos seres vivos 
são trabalhadas a partir de saberes e das disposições emocionais e afetivas dos estudantes e vão sendo organizadas a partir da orientação docente. Ainda, o foco da unidade é a percepção do corpo humano como um todo integrado e dinâmico, cuja manutenção e funcionamento dependem da integração entre as funções específicas de cada sistema. Destaca também aspectos relativos à saúde, entendida tanto como um estado de equilíbrio dinâmico do corpo quanto uma condição de assumir o protagonismo na escolha de posicionamentos que representem autocuidado com seu corpo e respeito com o corpo do outro, na perspectiva do cuidado integral à saúde física, mental, sexual e reprodutiva (BRASIL, 2017).

Considerando essa unidade temática proposta para os anos iniciais, bem como os aspectos de um corpo biológico e social, Porto e Porto (2012) destacam:

Atualmente o que se propõe é que o corpo humano seja proposto ao aluno como um sistema integrado, que interage com o ambiente e reflete a história de vida do seu sujeito. Considera-se por um lado que o corpo humano apresente um padrão comum que o identifique como espécie. Por outro lado, busca-se incorporar a este estudo a ideia que cada corpo é único, pois além das necessidades básicas gerais, existem aquelas individuais, próprias de cada sujeito, respeitando-se e valorizando-se as diferenças individuais (p. 35).

Nesse contexto, a ciência é compreendida como uma criação do ser humano e, por esse motivo, faz parte da sua cultura com o compromisso de ajudá-lo na resolução de problemas do seu cotidiano. É fundamental resgatar a ciência que faz parte do conhecimento escolar para, aí sim, realizar as transposições didáticas convenientes para seu ensino na escola. Assim, o ensino de ciência nos anos iniciais pode valer-se de uma série de metodologias que possibilitam envolver projetos de trabalho, resolução de problemas, sequências didáticas, momentos pedagógicos, entre outros. Nesse sentido, é importante que o professor tenha clareza quanto à concepção que irá orientar sua ação pedagógica (SALLES; KOVALICZN, 2007).

Diante de tal diversidade de metodologias, o ensino de ciência envolve também uma variedade de recursos didáticos possíveis de os docentes lançarem mão para o ensino dos conteúdos, como: saídas de campo (têm uma importância cognitiva na aprendizagem porque oferecem contato direto com a realidade), 
aulas práticas (incentivam a investigação científica desenvolvendo a habilidade de resolução de problemas), paródias (que passam a ser um instrumento educativo ao tornar conhecimentos científicos acessíveis de forma lúdica), maquetes (estimulam os sentidos e a criatividade como representações da realidade), produção de áudio/vídeo (estimulam a percepção sensorial e a criatividade), contos (contação de histórias estimula o imaginário e desperta a atenção), banco de imagens (demonstra o senso de organização e incentiva a pesquisa), teatro (privilegia a atividade coletiva, socializa, desinibe, possibilita interação social). Nesse sentido, a variedade de metodologias e recursos didáticos para o ensino de ciência facilita as aprendizagens por mobilizar as distintas capacidades cognitivas do estudante.

Considerando-se os propósitos desta pesquisa, tomou-se a Sequência Didática Interativa (SDI) como metodologia para a organização didática desenvolvida. A SDI é definida por Oliveira (2013) como um conjunto de atividades inter-relacionadas que demandam um planejamento para delimitação de cada etapa e/ou atividade para trabalhar os conteúdos de forma integrada. Uma SDI envolve as seguintes etapas: i) escolher o tema; ii) questionar para problematização do assunto a ser trabalhado; iii) planejamento dos conteúdos; iv) objetivos a serem atingidos no processo ensino-aprendizagem; v) delimitação da sequência de atividades, levando-se em consideração a formação de grupos, material didático, cronograma, integração entre cada atividade e etapas e avaliação dos resultados (OLIVEIRA, 2013). Como perfil docente ideal na condução de uma SDI, espera-se um professor questionador, mediador, pesquisador, dinâmico, interdisciplinar, disposto a compreender o mundo construído pelas gerações anteriores e desconstruir valores materializados e desatualizá-los pelo fato de não os reconhecer mais como fundamentais na atualidade (KINDEL, 2012). A partir desse contexto teórico, descreve-se a seguir a metodologia desenvolvida para a estruturação deste trabalho, pautada na descrição da SDI à luz das competências para o ensino de Ciências da Natureza (BRASIL, 2017), bem como dos conteúdos descritos por Zabala (1998). 


\section{Metodologia}

A pesquisa apresenta abordagem qualitativa, de cunho bibliográfico, contendo também características de um estudo documental. A abordagem qualitativa é definida por Bogdan e Biklen (1994) a partir de cinco características com as quais este estudo se identifica, quais sejam:

1 - Na investigação qualitativa a fonte direta de dados é o ambiente natural [...]; 2 - A investigação qualitativa é descritiva [...]; 3 - Os investigadores qualitativos interessam-se mais pelo processo do que simplesmente pelos resultados ou produtos [...]; $4-$ Os investigadores qualitativos tendem a analisar os seus dados de forma indutiva [...]; 5 -O significado é de importância vital na abordagem qualitativa [...] (p. 47-50).

Assim, este estudo foi desenvolvido com base nas cinco características propostas pelos autores supracitados, uma vez que a compreensão dos fenômenos no âmbito da área do ensino fica restrita se não forem considerados os aspectos destacados anteriormente. Para tanto, esta pesquisa envolveu um estudo bibliográfico realizado a partir do levantamento de referências já publicadas. No caso deste trabalho foram utilizados livros, artigos científicos e legislação acerca do ensino de Ciências. Para Fonseca (2002),

[...] qualquer trabalho científico inicia-se com uma pesquisa bibliográfica, que permite ao pesquisador conhecer o que já se estudou sobre o assunto, [...] procurando referências teóricas publicadas com o objetivo de recolher informações ou conhecimentos prévios sobre o problema a respeito do qual se procura a resposta (p. 32).

A classificação de estudo documental foi considerada pelo fato de esse tipo de análise envolver aspectos subjetivos expressos no material analisado (livro didático, registros das crianças e da professora e a BNCC). Os documentos oficiais, de acordo com Bogdan e Biklen (1994), têm sido considerados extremamente subjetivos por muitos pesquisadores. Essa consideração vem sendo feita tendo em vista que os textos produzidos para consumo externo podem apresentar um retrato ideal de como funciona o contexto analisado. Nesse 
sentido, os autores destacam que é exatamente pela característica subjetiva presente nesses documentos que estes tornam-se interessantes para a pesquisa qualitativa. São, portanto, as subjetividades presentes nestes documentos que interessam, pois auxiliaram na compreensão do quanto uma SDI pode contribuir para o ensino de Ciências.

Os instrumentos de coleta de dados foram os registros de estudantes e de uma docente do $5^{\circ}$ ano do Ensino Fundamental, de uma escola pública de periferia urbana do município de Santa Maria, RS, Brasil, durante oito horas/ aula de 50 minutos, no mês de novembro de 2016. Em relação aos registros da professora, consideraram-se os planos de aula e a organização das ideias na composição e na elaboração da SDI, tendo em vista a delimitação da temática a ser estudada, as etapas da sequência, os materiais e os recursos utilizados. Em relação aos materiais dos estudantes, foram analisadas produções como os textos, desenhos, tabelas, entre outros.

Para a análise dos achados procedeu-se com apoio nos princípios da Análise de Conteúdo descrita por Bardin (2011), na qual os procedimentos levam a relacionar estruturas semânticas e estruturas sociológicas dos enunciados, articulando os enunciados dos textos com fatores que determinam suas características psicossociais, contexto cultural e processos de produção de mensagem (MINAYO, 2001).

No contexto deste trabalho, estabeleceu-se uma associação entre as competências específicas das Ciências da Natureza (CNs) para o Ensino Fundamental (EF) descritas pela BNCC (BRASIL, 2017) (Quadro 1) e os Conteúdos Conceituais, Procedimentais e Atitudinais de Zabala (1998), adaptados para as especificidades das CNs. A partir de então, analisou-se a sequência da SDI, buscando-se evidenciar quais competências e conteúdos foram contemplados e algumas evidências sobre cada tipo acionado nos estudantes. Os conteúdos de Zabala (1998) adaptados às CNs foram:

- Conteúdos conceituais (aprender a conhecer): vocabulários específicos das Ciências, fatos e conceitos científicos e sua aplicação. 
- Conteúdos procedimentais (aprender a fazer): pesquisa e registros de dados, uso de ferramentas tecnológicas, capacidade de registro de informações por meio de diferentes linguagens.

- Conteúdos atitudinais (aprender a viver juntos, aprender a ser): habilidades de cooperação, de análise das consequências ao longo dos anos de uma alimentação inadequada, análise crítica em relação à higiene dos alimentos, cuidados com o desperdício, reaproveitamento, etc.

\section{Quadro 1 - Competências Específicas das Ciências da Natureza Propostas pela Base Nacional Comum Curricular Para o Ensino Fundamental}

1 - Compreender as ciências como empreendimento humano, reconhecendo que o conhecimento científico é provisório, cultural e histórico.

2 - Compreender conceitos fundamentais e estruturas explicativas das $\mathrm{CNs}$, bem como dominar processos, práticas e procedimentos da investigação científica, de modo a sentir segurança no debate de questões científicas, tecnológicas e socioambientais e do mundo do trabalho.

3 - Analisar, compreender e explicar características, fenômenos e processos relativos ao mundo natural, tecnológico e social, como também às relações que se estabelecem entre eles, exercitando a curiosidade para fazer perguntas e buscar respostas.

4 - Avaliar aplicações e implicações políticas, socioambientais e culturais da ciência e da tecnologia e propor alternativas aos desafios do mundo contemporâneo, incluindo aqueles relativos ao mundo do trabalho.

5 - Construir argumentos com base em dados, evidências e informações confiáveis e negociar e defender ideias e pontos de vista que respeitem e promovam a consciência socioambiental e o respeito a si próprio e ao outro, acolhendo e valorizando a diversidade de indivíduos e de grupos sociais, sem preconceitos de qualquer natureza.

6 - Conhecer, apreciar e cuidar de si, do seu corpo e bem-estar, recorrendo aos conhecimentos das CNs.

7 - Agir pessoal e coletivamente com respeito, autonomia, responsabilidade, flexibilidade, resiliência e determinação, recorrendo aos conhecimentos das CNs para tomar decisões diante de questões científico-tecnológicas e socioambientais e a respeito da saúde individual e coletiva, com base em princípios éticos, democráticos, sustentáveis e solidários.

Fonte: Brasil, 2017.

\section{Resultados e discussões}

Nos registros analisados constatou-se que a professora, ao elaborar a Sequência Didática Interativa (SDI), apresentada no Quadro 2, partiu de uma situação frequente na escola: o desperdício dos alimentos servidos na merenda 
e o desprezo destes pelas crianças ao preferirem alimentos industrializados, geralmente trazidos de casa. O desperdício é notável, tanto no chão do refeitório, por derrubarem alimentos, quanto nos próprios pratos, por não consumirem a totalidade do alimento servido. Assim, a postura dos estudantes em relação à merenda escolar motivou a delimitação do tema da SDI, denominado de "Alimentação Saudável”.

\section{Quadro 2 - Síntese da SDI desenvolvida na turma de $5^{\circ}$ ano acerca da alimentação saudável}

\begin{tabular}{|l|l|}
\hline \multicolumn{2}{|l|}{ CARACTERIZAÇÃO DA SEQUÊNCIA DIDÁTICA INTERATIVA } \\
\hline Público-alvo & 15 crianças do $5^{\circ}$ ano do EF. \\
\hline Duração & Duas semanas de aula ( $8 \mathrm{~h} / \mathrm{a}$ de 50 min). \\
\hline Tema & Alimentação saudável. \\
\hline Problema & Que alimentação é essa? \\
\hline Objetivo da SDI & $\begin{array}{l}\text { Instigar os estudantes do } 5^{\circ} \text { ano a refletirem sobre seus hábitos diante dos } \\
\text { alimentos. }\end{array}$ \\
\hline Conteúdos & $\begin{array}{l}\text { Ser humano e saúde: cuidados de si e do outro e dos ambientes, higiene e } \\
\text { alimentação saudável. }\end{array}$ \\
\hline $\begin{array}{l}\text { Objetivos de en- } \\
\text { sino a serem atin- } \\
\text { gidos }\end{array}$ & $\begin{array}{l}\text { Compreender o corpo como um bem pessoal e social. } \\
\text { Cultivar hábitos saudáveis para consigo e com os alimentos. } \\
\text { Reconhecer os alimentos como produtos da natureza. } \\
\text { Diminuir o desperdício de alimentos. } \\
\text { Reduzir o consumo de alimentos calóricos e industrializados. }\end{array}$ \\
\hline
\end{tabular}

Fonte: As autoras, 2017.

Na sala de aula, a conversa foi iniciada com um questionamento: "Por que há desperdício de alimentos na hora da merenda?", complementado pelas seguintes questões problematizadoras: "Será que as crianças não gostam da merenda oferecida na escola? Qual o tipo de lanche que as crianças gostariam de comer na escola?"

A partir da organização inicial, a professora desenvolveu uma sequência de atividades em consonância com os objetivos educativos presentes no Projeto Pedagógico da escola, elaborado pelos professores para o ano de 2016, cuja 
temática era "O cuidado de si, do outro e dos ambientes". Essa se mostrou passível de contemplar a alimentação saudável e a relação que se estabelece com a comida, seu consumo e potencial desperdício.

A professora, a partir da temática da alimentação saudável, levantada devido a um problema observado na escola, realizou o que orienta a BNCC ao sinalizar que as ações docentes devem

[...] contextualizar os conteúdos dos componentes curriculares, identificando estratégias para apresentá-los, representá-los, exemplificá-los, conectá-los e torná-los significativos, com base na realidade do lugar e do tempo nos quais as aprendizagens estão situadas (BRASIL, 2017, p. 12).

Desse modo, os estudantes foram sensibilizados a olharem para si, para seu cotidiano e, mais especificamente, para seus hábitos alimentares e vivências diante dos alimentos. Segundo Kindel (2012), a experiência educacional nos possibilita conhecer a nossa história e a complexidade do que existe hoje para poder participar do mundo e saber que é possível nos posicionarmos e agirmos ante o imprevisível.

Assim, a SDI teve sua ordem e conteúdo definidos pela professora, ou seja, decidiu-se quais atividades iriam fazer parte e qual seria a sequência ideal delas. O Quadro 3 apresenta uma síntese das etapas das atividades, bem como dos recursos priorizados. Acrescentou-se, na terceira coluna, as competências específicas das Ciências da Natureza definidas pela BNCC e, na quarta, os Conteúdos Conceituais (CCs), Procedimentais (CPs) e Atitudinais (CAs) percebidos. 
Quadro 3 - Síntese da SDI em relação à sequência de atividades, recursos didáticos, competências da BNCC e Conteúdos

\begin{tabular}{|c|c|c|c|c|}
\hline Etapas & Sequência de Atividades & $\begin{array}{l}\text { Recursos Didá- } \\
\text { ticos }\end{array}$ & $\begin{array}{l}\text { Competências da } \\
\text { BNCC das CNs }\end{array}$ & $\begin{array}{l}\text { Conteúdos (ZA- } \\
\text { BALA, 1998) }\end{array}$ \\
\hline A & $\begin{array}{l}\text { Classificação dos alimen- } \\
\text { tos em diet e light e iden- } \\
\text { tificação dos alimentos }\end{array}$ & $\begin{array}{l}\text { Livro didático } \\
\text { de Língua Por- } \\
\text { tuguesa (LDLP) }\end{array}$ & $2,3,5,6$ & $\mathrm{CC}, \mathrm{CP}$ \\
\hline B & $\begin{array}{l}\text { Consumo de alimentos } \\
\text { diet e light por crianças }\end{array}$ & LDLP & $2,6,7$ & $\mathrm{CC}, \mathrm{CP}, \mathrm{CA}$ \\
\hline $\mathrm{C}$ & $\begin{array}{l}\text { Hábitos alimentares das } \\
\text { crianças da escola do } \\
\text { turno da manhã }\end{array}$ & Questionário & $2,6,7$ & $\mathrm{CC}, \mathrm{CP}$ \\
\hline $\mathrm{D}$ & $\begin{array}{l}\text { Levantamento de dados } \\
\text { de } 21 \text { crianças }\end{array}$ & $\begin{array}{l}\text { Tabela Microsoft } \\
\text { Excel }\end{array}$ & $1,2,3,6$ & $\mathrm{CC}, \mathrm{CP}$ \\
\hline $\mathrm{E}$ & $\begin{array}{l}\text { Conceitos de vitaminas, } \\
\text { carboidratos, gorduras, } \\
\text { sais minerais e proteínas }\end{array}$ & Power Point & 2,6 & $\mathrm{CC}$ \\
\hline $\mathrm{F}$ & $\begin{array}{l}\text { Nutrientes presentes nos } \\
\text { alimentos }\end{array}$ & Vídeo e LDLP & 2,6 & $\mathrm{CC}$ \\
\hline G & $\begin{array}{l}\text { Pirâmide alimentar real } \\
\text { dos estudantes }\end{array}$ & $\begin{array}{l}\text { Pirâmide vazada } \\
\text { Desenhos }\end{array}$ & $1,2,3,6$ & $\mathrm{CC}, \mathrm{CP}, \mathrm{CA}$ \\
\hline $\mathrm{H}$ & Pirâmide alimentar ideal & Pesquisa Internet & $2,3,4,5,6,7$ & $\mathrm{CC}, \mathrm{CP}, \mathrm{CA}$ \\
\hline I & $\begin{array}{l}\text { Leitura de histórias acer- } \\
\text { ca da alimentação e hábi- } \\
\text { tos alimentares }\end{array}$ & $\begin{array}{l}\text { LDLP } \\
\text { Gibi Turma da } \\
\text { Mônica }\end{array}$ & $2,3,6,7$ & $\mathrm{CC}, \mathrm{CA}$ \\
\hline
\end{tabular}

Fonte: As autoras, 2017.

A partir da elaboração do Quadro 3, percebeu-se que as competências específicas das CNs não ocorrem sempre ou na mesma proporção em cada etapa, no entanto, considerando a totalidade da SDI, todas foram contempladas. Em relação aos CC, CP e CA, evidenciou-se a mesma tendência. Nesse sentido, serão discutidos os aspectos mais relevantes da SDI quando analisada à luz da política pública em questão e da teoria selecionada.

A competência 2 dá conta da compreensão dos conceitos e estruturas explicativas das CNs pelos estudantes, além do domínio dos processos, práticas e procedimentos de investigação científica. Percebe-se que essa possui relação semântica com os CC e CP, no entanto, algumas etapas da SDI (E, F e I) fo- 
ram identificadas possuindo essa competência somada apenas aos CC, sem a identificação dos CP. Isso se deu porque a competência 2 é mais abrangente, compreendendo conceitos e práticas/procedimentos das Ciências, enquanto os conteúdos abordam essas características (conceitos e procedimentos) separadamente. Dessa forma, nessas etapas identificou-se a compreensão dos conceitos com maior ênfase do que os procedimentos.

Nas etapas A e B, a partir do Livro Didático de Língua Portuguesa (LDLP) adotado na escola, os estudantes tiveram a oportunidade de realizar uma leitura acerca da classificação dos alimentos em diet e light.

A partir da imagem do interior de uma geladeira (Figura 1), o livro direcionou os estudantes a encontrarem alimentos considerados "verduras"/"legumes", frutas e laticínios (essa atividade deu-se de forma oral). Durante essa identificação, a professora questionou sobre os nomes dos vegetais, os quais, por vezes, eram desconhecidos dos estudantes. Um aspecto observado por eles foi o fato de alguns laticínios da imagem serem lights, algo inesperado para alguns dos estudantes. A partir dessa conversa inicial, os estudantes chegaram à conclusão de que as pessoas consumidoras dos alimentos da imagem são sujeitos que cuidam da alimentação "para não engordar". Com essas explanações os estudantes parecem associar a magreza com saúde, no entanto demonstraram compreender a redução calórica desses tipos de alimentos. Apesar do trabalho sobre alimentação saudável buscar a reeducação alimentar, mudanças de hábitos e a consequente diminuição do número de crianças obesas, é importante que o docente esteja atento para não reforçar imagens estereotipadas e preconceituosas acerca das pessoas com sobrepeso. 
Figura 1 - Imagem do Livro Didático de Língua Portuguesa

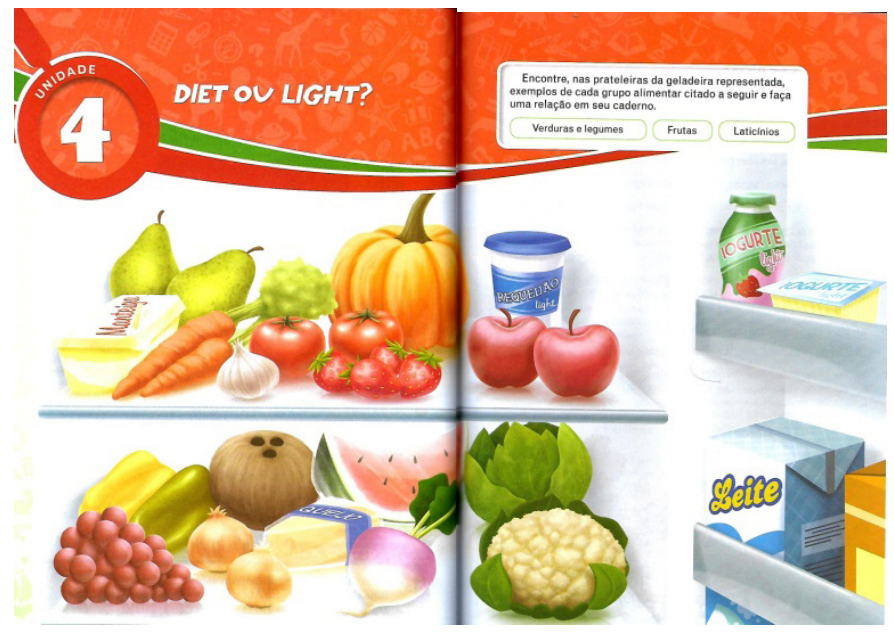

Fonte: PROGRAMA..., 2016, 2017, 2018.

A atividade B também fazia uso do LDLP, o qual apresentava uma reportagem, denominada "Lancheira Leve", contendo dados acerca de uma pesquisa realizada com crianças sobre seus hábitos alimentares na escola e o consumo de alimentos diet e light no seu lanche. Esse texto suscitou uma discussão na turma acerca dos motivos pelos quais as crianças estão aumentando o consumo desses tipos de alimentos (light e diet). Sobre esse aspecto, a professora foi repassando informações a respeito do valor nutricional de alimentos industrializados consumidos pelas crianças e seus efeitos no organismo. Essa discussão possibilitou às crianças compreenderem a importância de valorizar o alimento oferecido na merenda da escola, o qual é mais natural.

Destacamos que ambas as atividades desenvolveram alguns aspectos das competências 2 e 6 nos estudantes (além de outras, conforme Quadro 3). Ao compreenderem os conceitos e estruturas em relação aos tipos de alimento, a associação entre o valor nutricional destes e um possível emagrecimento, a valorização da merenda escolar por ser mais natural, além da leitura e da compreensão de dados de pesquisa científica, os estudantes mostram indícios do desenvolvimento de competências explicativas próprias das Ciências (Compe- 
tência 2). Além disso, aspectos do cuidado de si e de bem-estar (Competência 6) também foram identificados. Assim, percebeu-se que as duas etapas basearam-se no uso de diferentes tipos de conteúdos, investindo no aprender a conhecer e a fazer (CC e CP). Na etapa B, a partir da valorização da merenda escolar, considerou-se que os CA também foram trabalhados. Segundo Kindel (2012), a escola possui a tarefa de causar estranhamento e fazer refletir sobre os modos de ser e de fazer do mundo construído, negociando com os estudantes um novo olhar que dessa vez necessita ser compreendido pelas práticas de socialização no cotidiano escolar.

Observa-se que uma SDI provoca um vínculo com o conhecimento e, ao mesmo tempo, uma necessidade de se dar continuidade ao trabalho, aprofundando e gerando novas aprendizagens. A leitura e a interpretação da reportagem trabalhada na etapa B provocaram o interesse das crianças em investigar os hábitos alimentares dos estudantes do turno da manhã da escola. Esse interesse oportunizou a construção coletiva do instrumento de coleta de dados (questionário), utilizado na etapa subsequente (C) e aplicado aos estudantes do $4^{\circ} \mathrm{e}$ do $5^{\circ}$ ano. Nesse contexto, a professora aproveitou para explicar os princípios de uma pesquisa e como se pode elaborar um questionário a partir do qual se consegue obter informações a respeito de um grupo de pessoas. Dessa forma, segundo Morais e Andrade (2009), a docente ampliou o conceito de "pesquisa escolar" que os alunos geralmente possuem, apenas com o uso da biblioteca, Internet, livros didáticos, etc.

Responderam ao questionário 21 crianças e os resultados do levantamento foram organizados em tabelas e, posteriormente, em gráficos (etapa D). A organização em tabelas foi realizada oralmente pelas crianças e registrada no quadro da sala de aula, assim como os gráficos. Para a elaboração dos gráficos, as crianças desenharam "quadradinhos" que representavam a opinião dos colegas, sistematizando assim as quantidades de respostas. Posteriormente, a professora organizou as informações no Microsoft Excel (Figura 2) para uma apresentação dos dados diferenciada, com o uso das tecnologias. Os recursos tecnológicos apresentam grande potencialidade de despertar a atenção e de motivar os estudantes. Dessa forma, a alfabetização científica das crianças pode ser potencia- 
lizada ao ser oportunizada, concomitantemente, à alfabetização tecnológica. No entendimento de Morais e Andrade (2009, p.101), "o que se espera é que à medida que essas tecnologias se incorporem ao cotidiano das aulas, os professores passem a usar a sua criatividade para desenvolver estratégias que permitam explorar, os recursos, dando-lhes novas significações". Da mesma forma, para que a pesquisa fosse compreendida como um processo racional e sistemático, que requer tratamento científico podendo gerar novos conhecimentos, o trabalho realizado nas etapas $\mathrm{C}$ e D foi organizado em um relatório de pesquisa sobre alimentação, apoiado na teoria, oportunizando às crianças a compreensão das diferenças entre conhecimento empírico e conhecimento científico organizado.

Figura 2 - Organização dos dados da pesquisa sobre hábitos alimentares

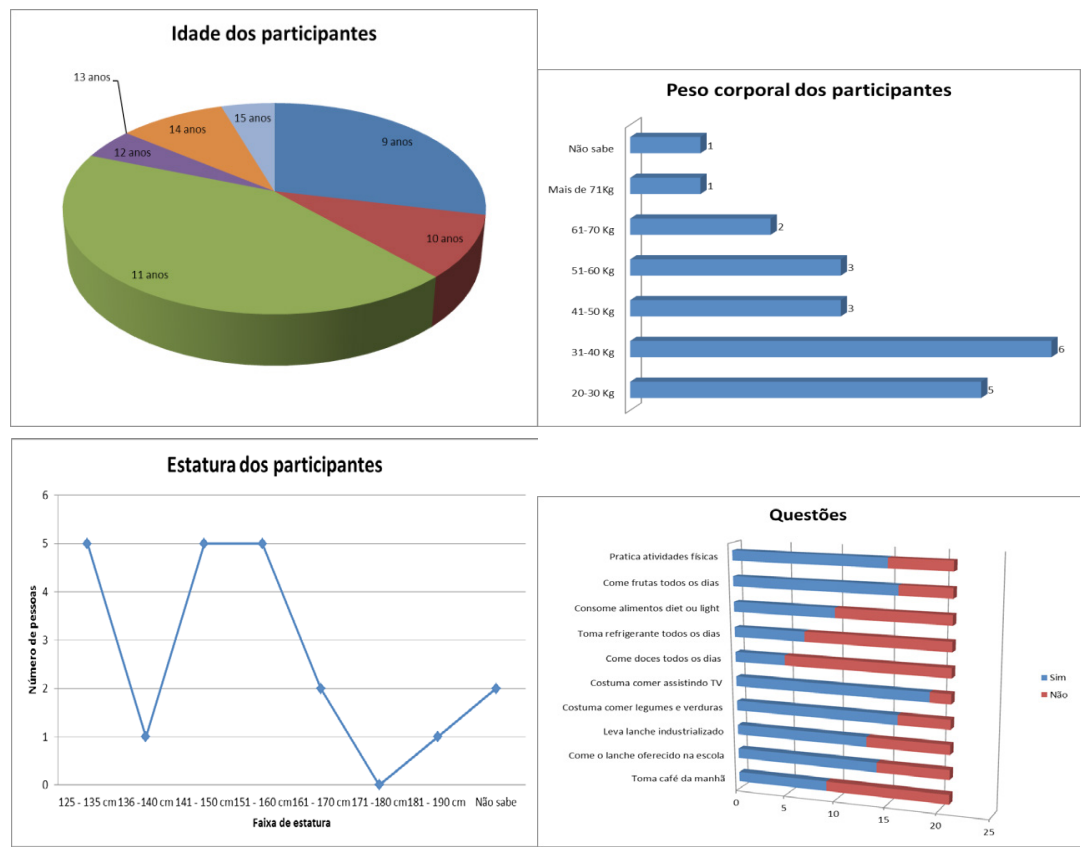

Fonte: As autoras, 2017. 
Nas etapas C e D, os alunos vivenciaram de forma mais aprofundada os processos e práticas de investigação das $\mathrm{CNs}$, aspectos próprios dos CP. Zabala (2007) destaca que ao se trabalhar os CP o aluno é levado a olhar o mundo e seu contexto com maior autonomia, responsabilidade, postura crítica e reflexiva referente aos diferentes assuntos estudados. Ainda, ao serem desafiados a construírem e a utilizarem um instrumento de coleta de dados (questionário), a levantarem hipóteses, realizarem registros dos dados, sistematizarem, interpretarem por meio de diferentes formas (relatos, gráficos, desenhos) e comunicarem os resultados, os alunos fizeram uso de procedimentos característicos da atividade científica. Tais atividades estiveram em consonância com a competência 6 (entre outras, conforme Quadro 3) da BNCC, a qual destaca a importância de o estudante ser capaz de analisar, compreender e explicar características, fenômenos e processos relativos ao mundo natural, tecnológico e social, como também às relações que se estabelecem entre eles, exercitando a curiosidade para fazer perguntas e buscar respostas (BRASIL, 2017).

Na etapa $\mathrm{E}$ foram trabalhados conceitos de vitaminas, carboidratos, gorduras, sais minerais e proteínas. Para essa tarefa a professora sistematizou esses conceitos em PowerPoint, a fim de que os estudantes compreendessem o que são e o papel de cada nutriente para o funcionamento do organismo humano. Essa etapa compreendeu uma aula expositiva-dialogada, objetivando a sistematização do conhecimento trabalhado até então. Na etapa $\mathrm{F}$ as crianças assistiram ao vídeo denominado Nutriamigos - É só você provar, ${ }^{4}$ no qual os nutrientes apresentam-se como um personagem, descrevendo suas funções nutricionais. Nessa fase a professora procurou destacar a relação entre uma alimentação colorida e o seu valor nutricional. Para tanto, utilizou como referência uma sistematização chamada “Boa alimentação”, disponível no Livro Didático de Língua Portuguesa.

${ }^{4}$ Publicado em 20 de fev. de 2014 - HGN Produtora - Desenho educativo dos Nutriamigos que é parte de um DVD com 5 vídeos sobre educação nutricional que estão sendo distribuídos gratuitamente em 3 mil escolas públicas do Estado de SP. Disponível em: <https://www.youtube.com/ watch?v=wv4kThJxKxQ $>$. 
Essas duas etapas oportunizaram a continuação do desenvolvimento das competências 2 e 6, bem como fez uso dos Conteúdos Conceituais. Ao longo da SDI, a professora recorreu diversas vezes ao Livro Didático (LD). Esse recurso configura-se, em muitas realidades brasileiras, como a única fonte de informação disponível para professores e alunos (NÚÑEZ et al., 2003). Para os autores, em algumas dessas realidades, o LD é considerado como uma estrutura "engessante" do currículo, por "prender" os sujeitos do processo educativo em atividades e conteúdos fixos no entanto percebeu-se no desenvolvimento da SDI que a professora utilizou o Livro Didático como um recurso a mais entre a diversidade de materiais disponibilizados aos estudantes. O LD desempenhou um papel importante durante a SDI, mas não um papel central. Seu uso fez sentido quando aliado aos demais recursos e às etapas da sequência, tendo suas potencialidades (imagens coloridas, textos de divulgação científica) exploradas com qualidade.

A etapa G, denominada de "Pirâmide Alimentar Real", pautou-se na utilização de uma folha de ofício contendo uma pirâmide vazada desenhada. Nessa, os estudantes foram convidados a registrar, em termos de quantidade, os alimentos que consomem diariamente. A Figura 3 ilustra três dessas pirâmides construídas pelos estudantes. A partir das pirâmides foi possível observar que os carboidratos e doces eram preponderantes na alimentação cotidiana das crianças. Já na etapa H, denominada de "Pirâmide Alimentar Ideal", a professora apresentou, em material fotocopiado, uma pirâmide alimentar ideal (Figura 4), aliada aos valores dos nutrientes apresentados no vídeo Nutriamigos. Essa etapa teve como objetivo confrontar os hábitos descritos nas pirâmides das crianças com as orientações nutricionais recomendadas para uma vida saudável.

Figura 3 - Pirâmide Alimentar Real representada pelos estudantes
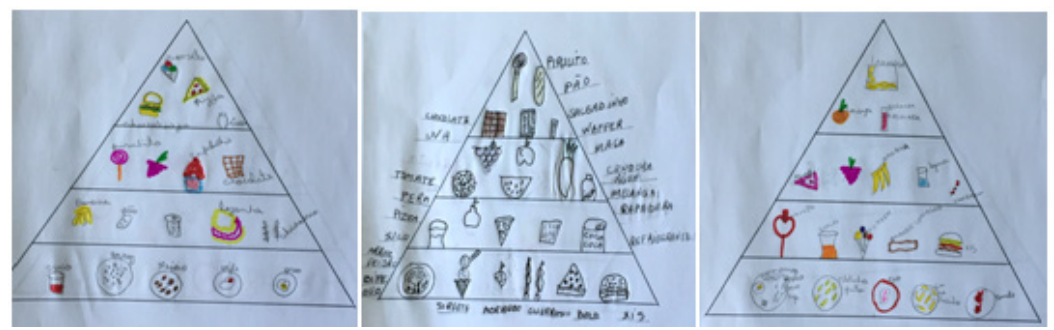

Fonte: Própria - produção dos estudantes, 2016. 
Figura 4 - Estrutura da Pirâmide Alimentar Ideal

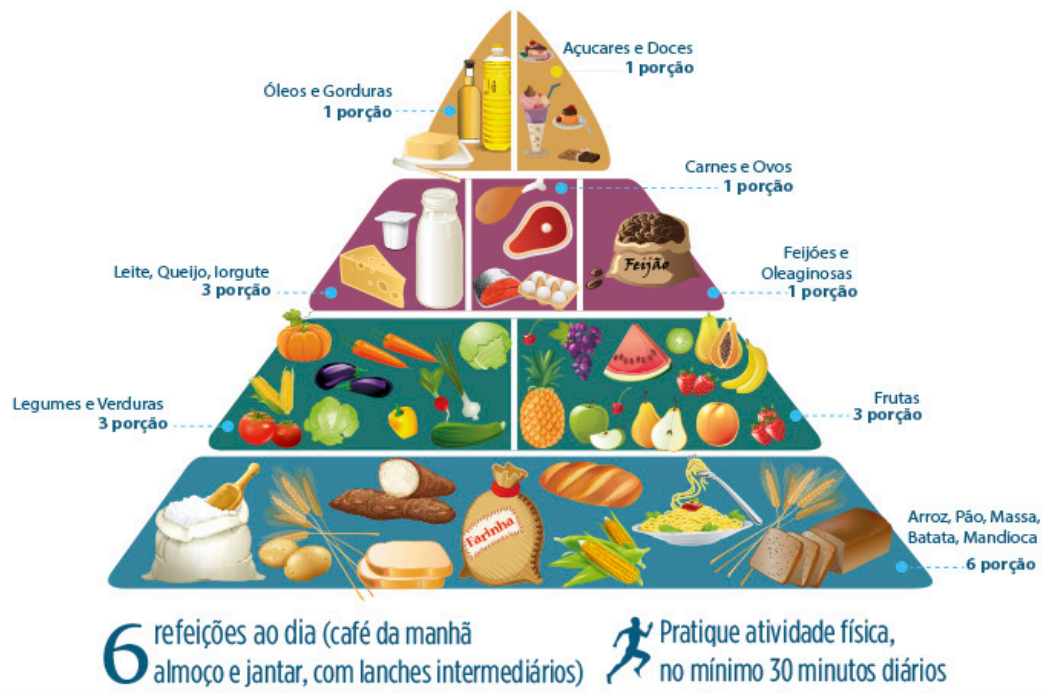

Fonte: Ministério da Saúde

Fonte: Brasil, 2014b.

Percebeu-se que as etapas $\mathrm{G}$ e $\mathrm{H}$ contemplaram os três tipos de conteúdos (conceituais, procedimentais e atitudinais). Foi necessário para as crianças refletirem e registrarem seus hábitos alimentares, fazendo uso de classificações por quantidade. Além disso, elas foram convidadas a comparar e a confrontar os resultados com uma fonte teórica, dialogando e argumentando seus achados e impressões. Um grande número de competências foi identificado a partir dessa atividade (Quadro 3). Destacamos a competência 5, atribuída à etapa H, a qual defende uma educação científica que forme sujeitos capazes de construírem argumentos com base em dados, evidências e informações confiáveis e negociarem e defenderem ideias e pontos de vista que respeitem e promovam o respeito a si próprio e ao outro (BRASIL, 2017). Para Amoedo et al. (2016), a educação científica oportuniza às crianças avanços cognitivos, no entanto é necessário que os docentes das primeiras etapas de escolarização estimulem e agucem sua aprendizagem, reconhecendo-a como um aparato de construção 
no desenvolvimento integral da criança pequena, compreendendo que o início da formação escolar é tão importante quanto o Ensino Superior, uma vez que insere o estudante no mundo científico (AMOEDO et al., 2016).

A etapa I envolveu a leitura de diferentes tipos de textos acerca da alimentação e hábitos alimentares. O primeiro deles, intitulado "Magralita", tratou-se de uma história infantil, de caráter ficcional, sobre uma menina que não gostava de comer nada. Esse texto, disponibilizado no LDLP, buscou contemplar a realidade de algumas crianças da turma que apresentavam problemas para comer vários tipos de alimentos, sendo muito restritivas. As atividades em torno desse texto envolveram a interpretação e a argumentação sobre o desfecho da personagem.

Outro texto utilizado nessa etapa explorou um gênero textual diferente dos anteriores, a História em Quadrinhos (HQ). Segundo Testoni e Abib (2003), a utilização das HQ envolve processos cognitivos, por parte do leitor, que abrangem a capacidade de imaginação, análise, síntese, decisão, além de outros mecanismos mentais necessários para a compreensão dessa narrativa. A história em questão era da Turma da Mônica, denominada "Alimentos Saudáveis" (Figura 5) e explorava a gula da personagem Magali, característica compartilhada com outro grupo de estudantes da turma. 
Figura 5 - História em quadrinhos (Alimentos Saudáveis)

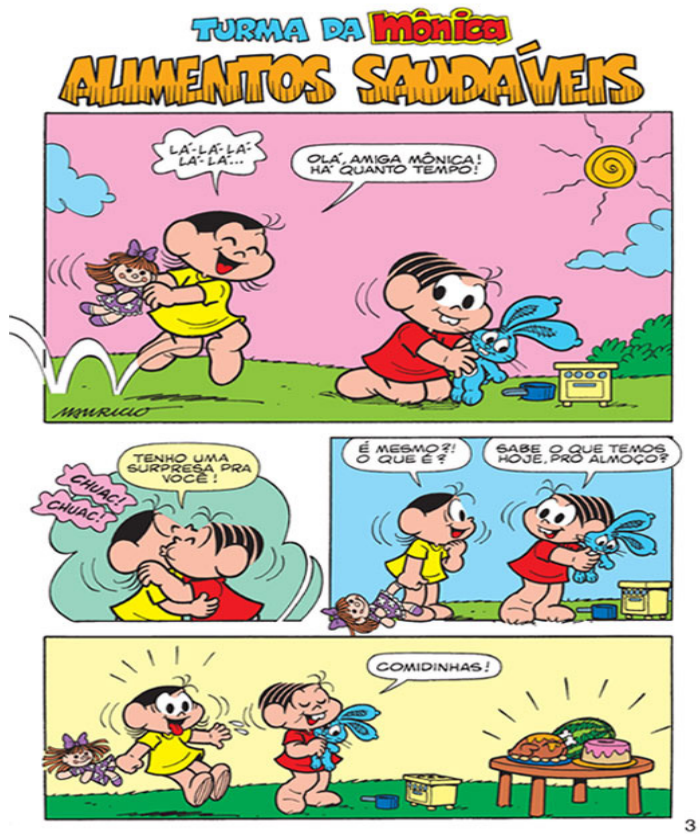

Fonte: <http://turmadamonica.uol.com.br/alimentos-saudaveis/>.

Essa etapa fez uso mais explícito dos Conteúdos Atitudinais ao descrever a postura dos personagens em relação à comida, permitindo aos estudantes repensarem suas próprias atitudes quanto à alimentação (restrição severa ou gula). Os alunos perceberam que tanto um comportamento quanto o outro não "fariam bem para a saúde", uma vez que necessitam de alimentos nutritivos, mas em quantidades adequadas. As histórias também se configuraram como importantes recursos na construção das competências 2, 3, 6 e 7 para as CNs da BNCC. Destaca-se, nessa etapa, a compreensão de conceitos (competência 2), a análise e a explicação de fenômenos e processos relativos ao mundo natural (competência 3), o conhecimento, a apreciação e o cuidado de si, do seu corpo e bem-estar, recorrendo aos conhecimentos das CNs (competência 6) e ação pessoal e coletiva, recorrendo aos conhecimentos das CNs para tomar decisões diante de questões de saúde individual e coletiva (competência 7) (BRASIL, 2017). 
Segundo Morais e Andrade (2009):

É importante que o educador em Ciências compreenda a necessidade de formar leitores capazes de compreenderem a linguagem da ciência, a necessidade de selecionar conteúdos relevantes, de estabelecer relações entre o lido e o conhecido, de questionar a confiabilidade da fonte consultada e de refletir sobre o informado, posicionando-se quanto a ele (p. 50).

Assim, conforme os estudantes progrediram no domínio da leitura, as histórias constituíram-se como recursos importantes na organização, na argumentação e na explicitação de seus conhecimentos sobre as Ciências da Natureza.

\section{Considerações Finais}

Por meio deste trabalho buscou-se analisar a adequação de uma Sequência Didática Interativa, mediante a exploração da temática da alimentação saudável, as competências específicas para as Ciências da Natureza propostas pela Base Nacional Comum Curricular e os Conteúdos Conceituais, Procedimentais e Atitudinais (ZABALA, 1998) adaptados às particularidades das CNs. A SDI desenvolvida apresentou potencialidades de valorização dos saberes prévios dos estudantes, oportunizando diversos momentos em que puderam expressá-los, além de uma mediação constante na consolidação de novos conhecimentos por meio do uso de variados recursos didáticos.

Conhecimentos esses que foram possibilitados a partir da exploração de conceitos, procedimentos e atitudes na elaboração da SDI e demonstrados, principalmente, nas evidências de consolidação de praticamente todas as competências pertinentes às $\mathrm{CNs}$ presentes na BNCC. Os estudantes demonstraram aprendizagem conceitual acerca dos nutrientes que compõem os alimentos, da diferença entre alimentos light e diet, da composição de uma pirâmide alimentar ideal para uma boa saúde. Apresentaram procedimentos de construção de um instrumento de coleta de dados, da sistematização de resultados a partir de pesquisa empírica, análise e interpretação dos dados, confrontação de achados, emissão de hipóteses e comunicação científica. Ainda valeram-se de atitudes em 
relação ao bem-estar e ao cuidado do próprio corpo, noções de sustentabilidade ao não desperdiçarem a merenda da escola e a passarem a valorizar o alimento mais natural.

Além disso, a SDI promoveu uma abordagem interdisciplinar dos conteúdos ao fazer uso da sistematização e organização de valores numéricos e da oralidade e leitura de diferentes gêneros textuais, característica essa tão cara aos anos iniciais do Ensino Fundamental e, por vezes, pouco efetivada nas escolas. Destaca-se também, a valorização das potencialidades do livro didático e a exploração de recursos de tecnologia, auxiliando na promoção de uma alfabetização tecnológica atrelada à alfabetização científica.

Por meio dessa atividade, acredita-se ter contribuído para a formação de sujeitos mais capazes de analisar e de agir criticamente quanto à própria alimentação e daqueles com quem convivem, adotando hábitos mais saudáveis, utilizando conceitos, procedimentos e atitudes próprios da ciência e consolidando os objetivos de se ensinar Ciências desde a infância, defendidos por pesquisadores da área e expressos nas políticas públicas educacionais do país.

\section{Referências}

ACCIOLY, E. A escola como promotora da alimentação saudável. Ciência em tela, v. 2, n. 2, 2009. Disponível em: <http://www.mobilizadores.org.br/wp-content/ uploads/2016/03/A-escola-como-promotora-da-alimentacao-saudavel.pdf $>$. Acesso em: 5 jun. 2017.

AMOEDO, F. K. F. et al. Educação científica: o desafio de ensinar cientificamente no contexto educacional infantil. Revista Amazônica de Ensino de Ciências - Areté, Manaus, v. 9, n. 19, p. 62-71, 2016. Disponível em: <http://periodicos.uea.edu.br:8080/index.php/ arete/article/view/221/220>. Acesso em: 16 maio 2017.

BARDIN, L. Análise de conteúdo. Ed. revista e ampliada. São Paulo: Edições 70 Brasil, 2011.

BOGDAN, R.C.; BIKLEN, S. K. Investigação qualitativa em educação: uma introdução à teoria e aos métodos. Trad. Maria João Alvarez, Sara Bahia dos Santos e Telmo Mourinho Baptista. Porto: Porto Editora, 1994. 
BRASIL. Lei de Diretrizes e Bases para a Educação Nacional no 9394, de 23 de dezembro de 1996. Disponível em: <http://www.planalto.gov.br/ccivil_03/leis/L9394.htm>. Acesso em: 30 jun. 2017.

Resolução CNS $n^{\circ} 408$, de 11 de dezembro de 2008. Aprova as diretrizes para a promoção da alimentação saudável. Disponível em: <http://criancaeconsumo.org.br/ wp-content/uploads/2014/02/cns408.pdf>. Acesso em: 18 jul. 2017.

Lei $n^{\circ} 11.947$, de 16 de junho de 2009. Dispõe sobre o atendimento da alimentação escolar e do Programa Dinheiro Direto na Escola aos alunos da educação básica. Disponível em: <https://www.fnde.gov.br/fndelegis/action/UrlPublicasAction. php?acao=getAtoPublico\&sgl_tipo=LEI\&num_ato $=00011947 \&$ seq_ato $=000 \& v 1 r$ ano=2009\&sgl_orgao=NI $>$. Acesso em: 15 jun. 2017.

Resolução CNE/CEB $n^{\circ}$ 4, de 13 de julho de 2010. Define Diretrizes Curriculares Nacionais Gerais para a Educação Básica. Disponível em: <http://portal.mec.gov. br/docman/julho-2013-pdf/13677-diretrizes-educacao-basica-2013-pdf/file >. Acesso em: 15 jun. 2017.

. Lei $n^{o}$ 13.005, de 25 de junho de 2014a. Aprova o Plano Nacional de Educação - PNE e dá outras providências. Disponível em: <http://www.planalto.gov.br/ ccivil_03/_ato2011-2014/2014/lei/113005.htm>. Acesso em: 23 jul. 2017.

. Ministério da Saúde. Secretaria de Atenção à Saúde. Departamento de Atenção Básica. Guia alimentar para a população brasileira. 2. ed., 1. reimpr. Brasília: Ministério da Saúde, 2014b. Disponível em: <http://bvsms.saude.gov.br/bvs/publicacoes/guia_alimentar_populacao_brasileira_2ed.pdf>. Acesso em: 17. out. 2016.

- Secretaria de Educação Básica. Diretoria de Apoio à Gestão Educacional. Pacto Nacional pela Alfabetização na Idade Certa: a organização do trabalho escolar e os recursos didáticos na alfabetização. Brasília: MEC; SEB, 2015. Disponível em: <http:// pacto.mec.gov.br/>. Acesso em: 27 mar. 2017.

. Ministério da Educação. Base Nacional Comum Curricular. Terceira versão. Brasília: MEC, 2017. Disponível em: <http://basenacionalcomum.mec.gov.br/images/ BNCC_publicacao.pdf>. Acesso em: 4 ago. 2017.

CHASSOT, A. Alfabetização científica: questões e desafios para a educação. 4. ed. Ijuí: Ed. Unijuí, 2006.

FONSECA, J. J. S. Metodologia da pesquisa científica. Fortaleza: UEC, 2002.

GONÇALVES, F. D. et al. A promoção da saúde na educação infantil. Interface - Comunic., Saúde, Educ., v. 12, n. 24, p. 181-92, 2008.

INSTITUTO BRASILEIRO DE GEOGRAFIA E ESTATÍSTICA (IBGE). Pesquisa de orçamento familiar, 2003. 
KINDEL, E. A. I. A docência em ciências naturais: construindo um currículo para o aluno e para a vida. Erechim, RS: Eldebra, 2012.

MINAYO, M. C. S. (Org.). Pesquisa social: teoria, método e criatividade. Petrópolis: Vozes, 2001.

MORAIS, M. B.; ANDRADE, H. P. Ciências ensinar e aprender: anos iniciais do ensino fundamental. Belo Horizonte: Dimensão, 2009.

NÚÑES, I. B. et al. A seleção dos livros didáticos: um saber necessário ao professor. O caso do ensino de Ciências. Revista Iberoamericana de Educación, 25 abr. 2003. Disponível em: <http://rieoei.org/deloslectores/427Beltran.pdf>. Acesso em: 13 jun. 2017.

OLIVEIRA, M. M. Sequência didática interativa no processo de formação de professores. Petrópolis, RJ: Vozes, 2013.

PATARRA N. L. Mudanças na dinâmica demográfica. In: MONTEIRO, C. A. (Org.). Velhos e novos males da saúde no Brasil. A evolução do país e de suas doenças. 2. ed. aumentada. São Paulo: Hucitec; Nupens; USP, 2006.

PORTO, L.; PORTO, A. Ensinar ciências da natureza por meio de projetos: anos iniciais do Ensino Fundamental. Belo Horizonte: Rona, 2012.

SALLES, G.; KOVALICZN, R. O mundo das ciências no espaço da sala de aula: o ensino como um processo de aproximação. In: NADAL, B. G. (Org.). Práticas pedagógicas nos anos iniciais: concepção e ação. Ponta Grossa, PR: VEPG, 2007.

SOCIEDADE BRASILEIRA DE ENDOCRINOLOGIA. Números de obesidade no Brasil, 2017. Disponível em: <https://www.endocrino.org.br/numeros-da-obesidade-no-brasil/>. Acesso em: 3 jul. 2017.

TESTONI, L. A.; ABIB, M. L. V. S. A utilização de histórias em quadrinhos no ensino de física: uma proposta para o ensino de inércia. In: ENCONTRO NACIONAL DE PESQUISA EM EDUCAÇÃO EM CIÊNCIAS, 4., 2003, Bauru. Anais... Disponível em: <http://fep.if.usp.br/ profis/arquivos/ivenpec/Arquivos/Orais/ORAL025.pdf>. Acesso em: 3 jul. 2017.

PROGRAMA NACIONAL DO LIVRO DIDÁTICO (PNLD). Coleção pequenos exploradores. Curitiba: Editora Positivo, 2016/2017/2018.

VALADÃO, M. M. Saúde e qualidade de vida. São Paulo: Global, 2003.

ZABALA, A. A prática educativa: como ensinar. Tradução Ernani F. da F. Rosa. Porto Alegre: Artmed, 1998.

. Enfoque globalizador e pensamento complexo: uma proposta para o currículo escolar. Porto Alegre: Artmed, 2007. 